\title{
Er det forskningsmessig interessant å koble data fra Medisinsk fødselsregister med data fra Kreftregisteret?
}

\author{
Steinar Tretli ${ }^{1,2}$, Tom Grotmol ${ }^{1}$ og Frøydis Langmark ${ }^{1}$ \\ ${ }^{1}$ Kreftregisteret \\ ${ }^{2}$ Institutt for samfunnsmedisin, NTNU \\ Korrespondanse: Steinar Tretli, Kreftregisteret, Montebello, 0310 Oslo \\ Telefon: $22451300 \quad$ Telefax: $22451370 \quad$ E-post: steinar.tretli@kreftregisteret.no
}

\begin{abstract}
SAMMENDRAG
Medisinsk fødselsregister og Kreftregisteret inneholder personidentifiserbare data som via fødselsnummeret kan kobles sammen innenfor de rammer som lovverket gir. Denne sammenkoblingen gir oss interessante muligheter til å studere fødselskarakteristikas betydning for risikoen for å få kreft senere i livet. På den måten vil vi også kunne få informasjon om hvilke mekanismer som er med å påvirke vår kreftrisiko. Det gir oss også muligheter til å studere hvilke konsekvenser kreftforekomst med påfølgende behandling kan ha både for senere svangerskap og barn som blir født.

Per 2006 er det akkumulert 12443 krefttilfeller blant de barn som er registrert i Medisinsk fødselsregister siden det ble etablert i 1967. Selv om dette er et betydelig antall krefttilfeller, er de fordelt på mange krefttyper, noe som har begrenset nytteverdien i kreftforskningen så langt. Imidlertid vil forskningsmulighetene øke med alderen til registeret. Også andre nordiske land har muligheter for slike koblinger, og til sammen gir dette unike muligheter til å gjennomføre interessant forskning.

I denne fremstillingen gis en kort presentasjon av gjennomførte og pågående vitenskapelige studier basert på sammenkobling mellom data fra Medisinsk fødselsregister og Kreftregisteret.
\end{abstract}

\section{INNLEDNING}

Medisinsk fødselsregister (MFR) fyller 40 år, og vi gratulerer med jubileet. Dette er en alder som $i$ andre sammenhenger blir oppfattet som at man er blitt voksen og ferdig med den urolige etableringsfasen. Når det gjelder kreftforekomst derimot, er MFR svært ungt. Likevel kan vi i denne artikkelen vise hvordan koblinger mellom MFRs og Kreftregisterets databaser har lagt grunnlaget for gode vitenskapelige studier. Avslutningsvis kommer vi med noen ord om fremtiden for den type forskning.

Ett av punktene i formålsparagrafen til MFR er å "fremskaffe kunnskap om årsaksforhold som grunnlag for forebyggelse av sykdom". Gjennomsnittsalderen ved kreftdiagnose er ca. 70 år for menn og 69 år for kvinner, og mindre enn $1 \%$ av krefttilfellene diagnostiseres før 15 års alder. Kreft er derfor ikke det første man tenker på ved livets begynnelse. Imidlertid har både arvelige forhold og gen-miljø-interaksjoner allerede i fosterlivet, vist seg å ha betydning for kreftforekomst mange tiår senere. Et eksempel på at en slik årsaksforståelse ikke bare er av nyere dato, finner vi i F.G. Gades bok fra 1929 (1): "Kreftsykdommene. Deres vesen, utbredelse og bekjempelse": "En åndrik hypotese til forklaring av kreftens fremkomst blev i 1877 fremsatt av den bekjente tyske patolog Julius Cohnheim. Han tenkte sig at kreftsvulstene utviklet seg fra visse cellegrupper, som tidlig i fosterets utvikling var kom- met ut av sin normale forbindelse, hadde forvillet sig og kommet på avveier, således at de var avleiret på uriktig plass, $i$ et fremmed vev. Her kunde de da ligge $i$ lange tider inntil senere hen i den fullt utviklede organismes liv et eller annet tilfeldig moment brakte dem til ny vekst og utvikling. Men de var blitt stående på det oprinnelige, embryonale utviklingstrinn og med tilsvarende egenskaper, også den å kunne utvikle sig på fremmed jordbunn, likesom de i egenskap av embryonale celler opptrer som fremmede snyltere $i$ den fullt utviklede organisme."

I 1990 lanserte Trichopoulos (2) en hypotese om at brystkreft kan ha sitt opphav i fosterlivet. Dette utløste en rekke forskningsprosjekter som forsøkte å undersøke denne problemstillingen. Ett av problemene knyttet til denne forskningen er mangel på data om eksponeringer eller påvirkninger som kunne knyttes til svangerskapet eller det nyfødte barnet. Det er derfor karakteristisk at fødselsvekt og -lengde har blitt hovedvariabler i disse studiene. Det eksisterer for brystkreft per i dag mer enn 20 publiserte studier på sammenhengen mellom fødselsvekt og brystkreft. Konklusjonen er at det er en konsistent og positiv assosiasjon mellom fødselsvekt og brystkreftforekomst (3). Data for fødselsvekt og -lengde finnes i MFR sammen med andre data for mor og barn, og som også kunne være interessante å relatere til brystkreftforekomst. Imidlertid er antall brystkrefttilfeller i den 40 år gamle "MFRkohorten" fortsatt i minste laget til å legge grunnlaget 
for gode studier. Det er viktig å være klar over at dataene i MFR (utover vekt og lengde) ikke er registrert spesifikt med henblikk på kreftforskning, og dataenes kvalitet vil derfor i noen tilfelle begrense forskningens kvalitet.

\section{STUDIER UTFØRT PÅ KOBLEDE DATA MELLOM MFR OG KREFTREGISTERET}

\section{Testikkelkreft}

Testikkelkreft er hyppigst forekommende mellom 20 og 40 års alder, noe som gjør denne kreftformen spesielt egnet for bruk av MFR-kohorten. Det er mange indikasjoner på at testikkelkreft initieres tidlig i livet kanskje allerede i fosterlivet. I tillegg til den lave alderen ved diagnose, underbygges fosterlivshypotesen av nordiske migrasjonstudier som viser at immigranter beholder risikoen for testikkelkreft fra sitt opprinnelige hjemland (4). Videre er fødselsår en viktig risikofaktor (3). Tilstandene testikkelkreft, hypospadi, kryptorkisme og lav sædkvalitet antas å ha felles etiologi med grunnlag i fosterlivet, og ofte brukes fellesbetegnelsen "testicular dysgenesis syndrome" (TDS). Den observerte økningen i disse tilstandene skyldes trolig hormonelle forstyrrelser under kritiske perioder i fosterlivet, for eksempel endringer $\mathrm{i}$ balansen mellom østrogener og androgener (østrogenhypotesen). En mer omfattende beskrivelse av hypotesen er gitt i (5).

I 1998 publiserte Wanderås og medarbeidere en studie av testikkelkreftforekomst basert på koblinger mellom MFR og Kreftregisteret (6). I denne studien ble det funnet en invers assosiasjon mellom paritet og testikkelkreft noe som kunne være til støtte for østrogenhypotesen. Det ble imidlertid gjort andre funn som ikke så klart kunne knyttes til denne hypotesen. Et slikt funn var en positiv sammenheng mellom neonatal icterus og senere testikkelkreft. Tilsvarende funn er også gjort i Sverige (7). Videre fant man en sammenheng mellom sykdom hos mor før svangerskapet og testikkelkreftforekomst. Det gjaldt spesielt for sykdommer i det urogenitale system, luftveisinfeksjoner, diabetes og rheumatoid arthritt. Forhøyet risiko ble også funnet etter svangerskap med placentainsufficiens og retinert placenta. De samme variablene er senere studert i en oppdatert og utvidet MFR-kohort av Aschim og medarbeidere i 2006 (8). Denne studien baserte seg på fire ganger så mange testikkelkrefttilfeller, og mesteparten av funnene er i samsvar med hva som ble funnet i det første arbeidet. Siden den nye studien var betydelig større, ga det også muligheter for å studere disse variablene relatert til forskjellige undergupper av testikkelkreft.

Siden hypospadi er en av tilstandene som inngår i TDS, ble de samme variablene fra MFR som inngikk i testikkelkreftprosjektet også studert i forhold til hypospadi (9). Assosiasjon med lav paritet, lav fødselsvekt og lav gestasjonsalder støtter hypotesen om felles risikofaktorer for TDS-tilstandene, og at hormonelle forstyrrelser under svangerskapet trolig er involvert. På samme måte som for testikkelkreft, viste det seg at retinert placenta representerte en økt risiko for hypospadi. Det hadde vært ønskelig å analysere de samme variablene med kryptorkisme som endepunkt, men registreringen av denne tilstanden $\mathrm{i} M F R$ var etter vår mening åpenbart mangelfull.

\section{Barnekreft}

Kreft som diagnostiseres i de første leveårene avviker på flere måter fra kreft som diagnostiseres i voksen alder. Kreft hos unge avviker både når det gjelder vevstype kreften utgår fra, mikroskopisk bilde og klinisk opptreden (10). I aldersgruppen 0-14 år er det per dato 4283 tilfeller av kreft i MFR-kohorten for begge kjønn samlet. Tallmessig er det derfor mulig å studere $i$ alle fall noen av krefttypene. Heuch et al. (11) undersøkte fødselskarakteristika og risikoen for Wilms' tumor. Studien dekket perioden 1967-92 og inkluderte 119 tilfeller. De fant en signifikant økt risiko med økende fødselslengde og også for lav Apgar score ved 1 minutt. Heuch et al. (12) har i tillegg studert hjernesvulst hos barn i den samme kohorten, som inkluderte 459 tilfeller av primær hjernesvulst. Resultatene antydet at risikofaktorene er forskjellige for ulike aldersgrupper (innen barnealderen) og for de histologiske undergruppene. I 2006 publiserte Samuelsen og medarbeidere (13) en oppfølgingsstudie av MFR-kohorten, og som nå dekket fødsler i perioden 1978-1998 og omfattet 453 hjernesvulsttilfeller. Spørsmålet var om hodeomkrets målt ved fødselen kunne assosieres med forekomst av hjernesvulst senere i barneårene. Hodeomkrets er registrert i MFR siden 1978. De fant at hjernesvulstrisikoen økte $27 \%$ for hver cm økning $\mathrm{i}$ hodeomkrets. Den positive sammenhengen ble funnet hos forskjellige undergrupper hjernesvulst, men for de fleste av gruppene var resultatet ikke signifikant. Vi har ikke funnet andre publikasjoner som har analysert denne assosiasjonen. Årsaken er trolig at det ikke eksisterer større kohorter hvor hodeomkrets er registrert og dermed kan studeres prospektivt.

\section{Kreft blant barn med medfodte misdannelser}

Betydningen av mors helse, retinert placenta etc. for risikoen for testikkelkreft kan indikere at forholdene under svangerskapet ikke har vært optimale, eller at det har vært omstendigheter som har medført høyere kreftrisiko. Arvelige forhold kan også spille inn. Medfødte misdannelser kan være et annet uttrykk for den samme ugunstige påvirkning av fosteret. Det første forsøket på å benytte seg av en kobling mellom MFR og Kreftregisteret i forskningssammenheng, var en studie av kreftforekomst hos barn som var registrert med misdannelser i MFR. Denne studien av Windham og medarbeidere fra 1985 (14), dekket fødselsperioden 1967-79 og var basert på kun 885 tilfeller av kreft, hvorav 42 var blant barn med misdannelser. Gruppen 
med registrerte misdannelser uansett type hadde en omtrent doblet risiko for kreft i forhold til de øvrige barna. Overrisikoen syntes begrenset til personer med Downs syndrom og defekter i sentralnervesystemet, og leukemi og CNS-svulster var hyppigst forekommende kreftformer. Det pågår en nyere studie som dekker perioden 1967-2001. For å få et enda bedre grunnlag for risikoestimater også for mer sjeldne misdannelser, er studien et fellesprosjekt med det medisinske fødselsregisteret i Sverige som startet sin virksomhet i 1973. Prosjektet ledes av Bjørge fra Universitetet i Bergen, og en publikasjon ventes å foreligge om kort tid.

\section{Andre prosjekter hvor MFR er brukt til å studere risikofaktorer for kreft}

Blant de personer som er registrert i MFR per 2006, var det 6466 mannlige og 5977 kvinnelige krefttilfeller, og de eldste kreftpasientene er 40 år. De hyppigst forekommende krefttyper blant menn og kvinner under 40 år er hjernesvulst, leukemi, lymfom, testikkelkreft, livmorhalskreft og malignt melanom. Det er derfor begrensede muligheter til å studere fødselskarakteristika og kreftrisiko hos individene i MFR-kohorten.

Iversen og medarbeidere (15) fant $\mathrm{i}$ en tvillingstudie at disse hadde halvparten av den forventede risiko for malignt melanom. Den forventede risikoen ble beregnet ut fra den generelle befolkning. Dette funnet har initiert en studie basert på en kobling mellom MFR og Kreftregisteret der hensikten først og fremst er å se på fødselsvektens betydning for risikoen for malignt melanom. Imidlertid vil også andre registrerte variabler undersøkes i den hensikt å generere hypoteser. Studien ledes av Franco-Lie.

Det er også andre problemstillinger som kan belyses gjennom en kobling mellom MFR og Kreftregisteret, som for eksempel å undersøke om MFR-data kan knyttes til kreftrisiko senere i livet hos foreldrene. For eksempel er det kjent fra case-control-studier (16) at en kvinne som har hatt pre-eklampsi eller hypertensjon under svangerskapet, kan ha en lavere risiko for brystkreft senere i livet. Vatten og medarbeidere (17) har brukt MFR-kohorten koblet mot Kreftregisteret til å undersøke dette prospektivt. Deres resultater støtter tidligere funn som antyder at patofysiologiske tilstander, som pre-eklampsi og hypertensjon knyttet til svangerskapet, er viktig for kvinnens brystkreftrisiko. Den samme forskergruppen har i en tilsvarende koblingsstudie mellom MFR og Kreftregisteret funnet en invers sammenheng mellom varigheten av svangerskapet og senere brystkreftrisiko (18).

Det er kjent fra flere studier at antall svangerskap og alder ved svangerskapene innvirker på risikoen for ulike typer kreft (19). Vatten og medarbeideres resultater (18) bekrefter tidligere studier som viser at lav alder ved første fødsel og antall barn som kvinnen har født, reduserer risikoen for brystkreft. Per i dag finnes det andre og større databaser som gir bedre muligheter for å teste disse hypotesene. Hormonelle og immuno- logiske forhold relatert til selve svangerskapet kan ha negativ effekt på kreftutvikling. For eksempel har kvinner som får diagnosen brystkreft under svangerskapet eller i perioden like etter, en dårligere prognose. Reed og medarbeidere (20) har gjennomført en slik studie blant mødre som er identifisert gjennom MFR og Kreftregisteret. For tiden pågår en studie av Stensheim og medarbeidere ved helseforetaket Rikshospitalet-Radiumhospitalet for å se på sammenhengen mellom kreftrelatert overlevelse blant pasienter som er diagnostisert i tilknytning til svangerskap.

\section{Behandling i forbindelse med kreft kan tenkes å ha konsekvenser både for svangerskapet og for barnet}

Lund og Bjerkedal (21) benyttet en kobling mellom MFR og Kreftregisteret i 1986 til å studere konsekvensene av konisering blant 570 kvinner som hadde fått påvist in situ-lesjoner i livmorhalsen. De ble sammenlignet med like mange kontroller, og til sammen representerte disse to gruppene 1835 fødsler. De fant at kirurgisk fjerning av livmorhalstappen var assosiert med en sterkt økt risiko for perinatal død og for å føde barn med lavere fødselsvekt.

Humant papillomavirus (HPV) synes å være en nødvendig faktor i utviklingen av livmorhalskreft. Det er derfor gjennomført et større vaksinasjonsforsøk for å forebygge slike infeksjoner i den hensikt å redusere risikoen for livmorhalskreft. Det er planlagt at deltakerne i studien (registrert i Kreftregisteret) skal følges i MFR for å se om vaksinasjonen kan ha innvirket på svangerskapet og fosteret. Etter hvert som vaksinen tilbys også andre kvinner og det opprettes et vaksinasjonsregister, planlegges det at også disse kvinnenes svangerskap blir fulgt via MFR.

Stensheim og medarbeidere, som referert til over, vil også se på forekomsten av fødsler blant foreldre som har hatt kreft, og om kvinnene har økt risiko for komplikasjoner under svangerskapet eller i perinatalperioden. Disse studiene utføres med basis i en kobling mellom MFR og Kreftregisteret. Spesialregistre med kliniske opplysninger og behandlingsbeskrivelser er for tiden under etablering ved Kreftregisteret. Det vil etter hvert være interessant å benytte disse til å undersøke om ulike behandlingsmetoder kan bety noe for dem som velger å få barn etter kreftdiagnosen. Dette kan være aktuelt både når det er mor og far som har hatt kreft.

Kreftregisteret har også brukt MFR til å identifisere gravide som på samme tid er invitert til livmorhalsscreeningen. Resultatene viser at svangerskap bidrar til å øke fremmøteprosenten ved screeningen (22).

\section{FREMTIDEN}

Den type data som finnes i MFR er potensielt meget verdifull $\mathrm{i}$ forhold til mange ulike former for kreftforskning. Foreløpig er MFR i yngste laget til å kunne utnytte dette fullt ut, men antall krefttilfeller vil selv- 
sagt øke ettersom MFR-kohorten øker i alder og omfang. Etter hvert vil det åpne seg muligheter for i større omfang å studere familierelasjoner og kreft, og da spesielt kontraster i fødselskarakteristika og senere utfall mellom søsken. Videre kan man tenke seg å knytte fødselskarakteristika hos mor og barn med eksponeringsdata senere i livet og kreftforekomst. Slike studier ligger trolig 10-30 år fram i tid, og i mellomtiden må man nøye seg med å plukke de "frukter" som er modne.

\section{REFERANSER}

1. Gade FG. Kreftsykdommene. Deres vesen, utbredelse og bekjempelse. Steenske forlag, Oslo, 1929.

2. Trichopoulos D. Hypothesis: does breast cancer originate in utero? Lancet 1990; 335: 939-40.

3. Tretli S, Weiderpass E, Grotmol T. Conditions in utero and cancer risk. Norsk Epidemiologi 2005; 15: 55-63.

4. Ekbom A, Richiardi L, Akre O, Montgomery SM, Sparen P. Age at immigration and duration of stay in relation to risk for testicular cancer among Finnish immigrants in Sweden. J Natl Cancer Inst 2003; 95: 1238-40.

5. Sharpe RM. The "oestrogen hypothesis" - where do we stand now? Int J Androl 2003; 26: 2-15.

6. Wanderaas EH, Grotmol T, Fossa SD, Tretli S. Maternal health and pre- and perinatal characteristics in the etiology of testicular cancer: a prospective population- and register-based study on Norwegian males born between 1967 and 1995. Cancer Causes Control 1998; 9: 475-86.

7. Akre O, Ekbom A, Hsieh CC, Trichopoulos D, Adami HO. Testicular nonseminoma and seminoma in relation to perinatal characteristics. J Natl Cancer Inst 1996; 88: 883-9.

8. Aschim EL, Haugen TB, Tretli S, Daltveit AK, Grotmol T. Risk factors for testicular cancer - differences between pure non-seminoma and mixed seminoma/non-seminoma? Int J Androl 2006; 29: 458-67.

9. Aschim EL, Haugen TB, Tretli S, Daltveit AK, Grotmol T. Risk factors for hypospadias in Norwegian boys association with testicular dysgenesis syndrome? Int J Androl 2004; 27: 213-21.

10. Little J. Epidemiology of Childhood Cancer. IARC Scientific Publications No 149, Lyon, 1999.

11. Heuch JM, Heuch I, Kvale G. Birth characteristics and risk of Wilms' tumour: a nationwide prospective study in Norway. Br J Cancer 1996; 74: 1148-51.

12. Heuch JM, Heuch I, Akslen LA, Kvale G. Risk of primary childhood brain tumors related to birth characteristics: a Norwegian prospective study. Int J Cancer 1998; 77: 498-503.

13. Samuelsen SO, Bakketeig LS, Tretli S, Johannesen TB, Magnus P. Head circumference at birth and risk of brain cancer in childhood: a population-based study. Lancet Oncol 2006; 7: 39-42.

14. Windham GC, Bjerkedal T, Langmark F. A population-based study of cancer incidence in twins and in children with congenital malformations or low birth weight, Norway, 1967-1980. Am J Epidemiol 1985; 121: 49-56.

15. Iversen T, Tretli S, Kringlen E. An epidemiological study of cancer in adult twins born in Norway 1905-1945. Br J Cancer 2001; 84: 1463-5.

16. Ekbom A, Trichopoulos D, Adami HO, Hsieh CC, Lan SJ. Evidence of prenatal influences on breast cancer risk. Lancet 1992; 340: 1015-8.

17. Vatten LJ, Romundstad PR, Trichopoulos D, Skjaerven R. Pre-eclampsia in pregnancy and subsequent risk for breast cancer. Br J Cancer 2002; 87: 971-3.

18. Vatten LJ, Romundstad PR, Trichopoulos D, Skjaerven R. Pregnancy related protection against breast cancer depends on length of gestation. Br J Cancer 2002; 87: 289-90.

19. Hankinson S, Hunter D. Breast cancer. In: Adami HO, Hunter D, Trichopoulos D, eds. Textbook of Cancer Epidemiology. Oxford: Oxford University Press, 2002: 315.

20. Reed W, Hannisdal E, Skovlund E, Thoresen S, Lilleng P, Nesland JM. Pregnancy and breast cancer: a population-based study. Virchows Arch 2003; 443: 44-50.

21. Lund E, Bjerkedal T. Cancer in situ of the uterine cervix. Increased perinatal death and prematurity after conization. Tidsskr Nor Laegeforen 1986; 106: 543-6.

22. Nygard M, Daltveit AK, Thoresen SO, Nygard JF. Effect of an antepartum Pap smear on the coverage of a cervical cancer screening programme: a population-based prospective study. BMC Health Serv Res 2007; 7: $10-7$. 